\title{
Safety and feasibility of thoracoscopic esophagectomy after neoadjuvant chemotherapy for esophageal cancer
}

Yushi Fujiwara, Shigeru Lee, Satoru Kishida, Ryoya Hashiba, Ken Gyobu, Masashi Takemura, Harushi Osugi

\begin{tabular}{|c|l|}
\hline Citation & Surgery Today, $47(11) ; 1356-1360$ \\
\hline Issue Date & $2017-11$ \\
\hline Type & Journal Article \\
\hline Textversion & Author \\
\hline Relation & $\begin{array}{l}\text { This is a post-peer-review, pre-copyedit version of an article published in Surgery } \\
\text { Today. The final authenticated version is available online at: } \\
\text { https://doi.org/10.1007/s00595-017-1526-6 }\end{array}$ \\
\hline DOI & $\begin{array}{l}\text { This is the accept manuscript version. Please cite only the published version. } \\
\text { 引用の際には出版社版をご確認ください。 }\end{array}$ \\
\hline
\end{tabular}

\author{
Self-Archiving by Author(s) \\ Placed on: Osaka City University
}

FUJIWARA Y, LEE S, KISHIDA S, HASHIBA R, GYOBU K, TAKEMURA M, \& OSUGI H. (2017). 
ORIGINAL ARTICLE

Safety and feasibility of thoracoscopic esophagectomy after neoadjuvant chemotherapy for esophageal cancer

\section{ST-2016-0727-CO.R2}

Yushi Fujiwara $^{1} \cdot$ Shigeru Lee $^{1} \cdot$ Satoru Kishida $^{1} \cdot$ Ryoya Hashiba $^{1} \cdot$ Ken Gyobu $^{1} \cdot$ Masashi Takemura $^{2}$. Harushi Osugi ${ }^{3}$

${ }^{1}$ Department of Gastroenterological Surgery, Osaka City University Graduate School of Medicine

${ }^{2}$ Department of Upper Gastrointestinal Surgery, Hyogo College of Medicine

${ }^{3}$ Department of Surgery, Institute of Gastroenterology, Tokyo Women's Medical University

\section{Correspondence to:}

Yushi Fujiwara,

Department of Gastroenterological Surgery, Osaka City University Graduate School of Medicine, 1-4-3

Asahi-machi, Abeno-ku, Osaka 545-8585, Japan

Tel. +81-6-66453841; Fax +81-6-66466057

e-mail: fujiwaray@msic.med.osaka-cu.ac.jp

The article type: Clinical Original Article

Key words Esophageal carcinoma, Neoadjuvant chemotherapy, Thoracoscopic esophagectomy 


\begin{abstract}
Purpose Neoadjuvant chemotherapy (NAC) with cisplatin and fluorouracil is the recommended standard treatment for resectable locally advanced esophageal cancer (EC) in Japan. We investigated the effects of NAC on the safety and feasibility of thoracoscopic esophagectomy with total mediastinal lymphadenectomy for EC.

Methods This retrospective study analyzed data from 225 consecutive patients who underwent thoracoscopic esophagectomy with lymph node dissection between April, 2007 and December, 2015. Patients with clinical stage IB, IIA, IIB, IIIA, or IIIB EC, and no active concomitant malignancy were included. We compared intraoperative outcomes, and postoperative morbidity and mortality between 139 patients who received NAC (NAC group) and 86 patients who did not (non-NAC group).

Results Preoperative laboratory data revealed that anemia, thrombopenia, and renal dysfunction were more common in the NAC group than in the non-NAC group. There were no differences between the groups in operating times, blood loss, number of dissected lymph nodes, overall complication rates, or length of postoperative hospital stay.

Conclusion Based on our findings, thoracoscopic esophagectomy is safe and effective for locally advanced EC, even after NAC.
\end{abstract}




\section{Introduction}

Esophageal cancer (EC) is the sixth leading cause of cancer-related mortality and the eighth most common cancer worldwide [1]. Esophageal squamous cell carcinoma (ESCC) accounts for about $90 \%$ of esophageal cancers worldwide [1,2], and it is also the predominant histological type of EC in Japan [3]. Surgery is the standard treatment for resectable EC and although surgical techniques have been refined, advanced EC carries a poor prognosis. Multimodal therapy, including chemotherapy, radiotherapy and surgical resection, is necessary, and randomized clinical trials have been performed to evaluate therapeutic regimens that may improve disease outcomes [1-4]. Several randomized controlled trials have been conducted by the Japan Clinical Oncology Group (JCOG) in Japanese patients with resectable locally advanced ESCC. In the JCOG9907 trial [5], preoperative chemotherapy was associated with a survival benefit over postoperative chemotherapy for patients with locally advanced ESCC. Based on this result, NAC with cisplatin and fluorouracil is now recommended for resectable locally advanced ESCC in Japan [3]. At our institution, NAC was introduced in 2008 and has been delivered in earnest since 2010. The JCOG9907 trial demonstrated that rates of major perioperative complications did not differ between the preoperative and postoperative chemotherapy groups [5,6]. These findings concur with those from recent large-scale clinical trials comparing NAC followed by surgery vs. surgery alone $[7,8]$. However, we often find edematous and fibrous tissue changes in the mediastinal surgical field, which makes the procedure more difficult, and surgery after NAC is suggested to be more technically challenging. At our institution, thoracoscopic esophagectomy (ThE) with total mediastinal lymphadenectomy for EC has been the standard therapeutic approach for EC since its introduction in 1995 and more than 600 patients have undergone this procedure. The number of patients receiving ThE after NAC is increasing. We investigated retrospectively whether NAC influences the safety and feasibility of esophagectomy in a series of patients who underwent ThE with total mediastinal lymphadenectomy for EC

\section{Patients and Methods}

\section{Neoadjuvant chemotherapy}


Neoadjuvant chemotherapy is indicated for locally advanced ESCC of clinical T2-3 or clinical T1-3 with regional lymph node metastasis (clinical stage IB, IIA, IIB, IIIA, or IIIB). At our institution, NAC was introduced in 2008. Initially, the implementation of NAC depended on the attending doctor, but since 2010, almost all suitable candidates have received NAC after giving informed consent.

\section{Patients and data collection}

The subjects of this study were consecutive patients who underwent ThE, with or without NAC, at Osaka City University Hospital (Osaka, Japan) between April, 2007 and December, 2015. Criteria for eligibility in this study were as follows: thoracic EC in clinical stage IB, IIA, IIB, IIIA, or IIIB; histologically confirmed squamous cell carcinoma; esophagectomy with radical lymph node dissection; Eastern Cooperative Oncology Group performance status $0-2$ with adequate organ function; and no active concomitant malignancy. Computed tomography, endoscopic ultrasound and positron emission tomography, if feasible, were used for staging work-ups. ThE was not indicated for patients with pulmonary function, incapable of sustaining single-lung ventilation; those with extensive pleural adhesions; those with contiguous invasion to adjacent tissues; those who had received prior radiation therapy; and those who declined to undergo the procedure [9]. The indications for ThE were the same for patients with or those without NAC. Written comprehensive informed consent approved by the Institutional Review Board was obtained from all patients before treatment.

\section{NAC regimen}

Based on the JCOG9907 trial [5], two cycles of chemotherapy were administrated, in principle. Chemotherapy was given as an intravenous infusion of cisplatin $(80 \mathrm{mg} / \mathrm{m} 2)$ for $2 \mathrm{~h}$ on day 1 , with a continuous infusion of fluorouracil $(800 \mathrm{mg} / \mathrm{m} 2)$ from day 1 to day 5 , with an interval of 4 weeks between the first day of each cycle. Patients who did not respond to the first cycle of chemotherapy did not receive the second cycle. Surgical resection was scheduled for 4 to 5 weeks after completing NAC.

\section{Surgical procedures}

All patients underwent ThE with radical lymph node dissection. They also underwent laparotomy for the creation of gastric tubes with reconstruction done via the posterior mediastinum, with anastomosis in the 
neck. According to the Japanese guidelines for clinical and pathological studies on carcinoma of the esophagus [3], D2 lymph node dissection was performed. During the thoracoscopic procedure, patients were placed in the left lateral decubitus position. The right lung was deflated with split ventilation. A 5$\mathrm{cm}$ mini-thoracotomy was made in the 5th intercostal space on the anterior axilla line, and four $11-\mathrm{mm}$ trocars were inserted around the mini-thoracotomy, as described previously [9]. The surgeon and assistants were in the same positions as for open surgery, with the monitor image at a reversed horizontal angle from the surgeon and vertically from the assistants. This setup allows the surgeon good eye-hand coordination for the entire mediastinum. Esophagogastric anastomosis was constructed in the cervical area using a circular stapling device. In both groups, all operations were performed by the same surgical team.

\section{Perioperative analysis}

We collected clinical data from the patient database of Osaka City University Hospital. Retrospective data on intraoperative factors and postoperative morbidity and mortality after thoracoscopic radical esophagectomy were compared between patients with and those without NAC. Tumor staging was done using the 7th edition of the Union for International Cancer Control (UICC) tumor-node-metastasis cancer staging system [10]. Among postoperative complications, pneumonia was diagnosed if a patient had infiltrate on chest imaging studies with associated fever or elevated white blood cell count. Recurrent laryngeal nerve paralysis was defined as disturbance of vocal cord mobility by a flexible scope after extubation. Anastomotic leakage were defined as evidence of contrast extravasation at esophagogastric anastomosis or direct clinical observation. Chyle leakage was diagnosed by a change in quality of the pleural fluid, from serous to milky or yellowish. For analyzing postoperative complications, all grades of the JCOG criteria [11] were extracted.

\section{Statistical analysis}

Patient data were analyzed using JMP 12 software (SAS Institute, Cary, NC, USA). Continuous variables were analyzed using the Mann-Whitney U-test. The chi-square or Fisher's test were used to compare categorical variables between groups. $\mathrm{P}<0.05$ (two-sided) was considered significant. 


\section{Results}

\section{Patient characteristics (Table 1)}

A total of 225 patients were enrolled in this study, 139 of whom underwent ThE after NAC (NAC group) and 86 of whom underwent ThE without NAC (non-NAC group). The two groups did not differ significantly in age, sex, or tumor location. Because NAC was indicated principally for patients with regional lymph node metastasis, the percentage of patients with advanced disease was higher in the NAC group $(\mathrm{P}<0.001)$. Preoperative laboratory data showed that anemia, thrombopenia and impaired renal function were more common in the NAC group than in the non-NAC group $(\mathrm{P}<0.05)$. Although the scheduled interval between completing chemotherapy and surgery was considered adequate, bone marrow suppression and renal dysfunction caused by chemotherapy were present at the time of surgery.

\section{Operative outcomes (Table 2)}

Conversion to open thoracotomy was required for 14 NAC patients $(10.7 \%)$ and 6 non-NAC patients (7.0\%) The main reasons for conversion were the intraoperative diagnosis of contiguous organ invasion with severe and pleural adhesion. There were no differences between the groups in operation time or blood loss. Although anemia was more frequent in the NAC group, the intraoperative transfusion rate did not differ. Numbers of dissected lymph nodes were similar in the two groups. The feasibility of ThE performed after NAC was equivalent to the operation without NAC, from a qualitative viewpoint.

\section{Postoperative morbidity and mortality (Table 3)}

The two groups did not differ significantly in the overall frequency of complications. One non-NAC patient died of multiple organ dysfunction syndrome related to postoperative hemorrhagic shock. The two groups did not differ in length of hospitalization. Thus, the safety of ThE after NAC was equivalent to that of esophagectomy alone.

\section{Discussion}


The prognosis of patients with advanced EC remains poor, despite evaluations of various treatment strategies with different agents to improve outcomes [1-4]. Nevertheless, neoadjuvant therapy followed by surgical resection has become the worldwide standard of care for resectable locally advanced EC [1, 2]. Neoadjuvant chemoradiation therapy is commonly used in the USA, whereas NAC is a more common approach in Europe [1]. In Japan, several trials have been conducted for resectable locally advanced EC. Among them, the JCOG9907 study [5] compared preoperative chemotherapy with postoperative chemotherapy (cisplatin and fluorouracil) for patients with resectable stage II or III (UICC 6th) thoracic ESCC. The results demonstrated significantly improved overall survival in the NAC group. Accordingly, NAC with cisplatin and fluorouracil followed by surgical resection is the now the standard treatment for resectable locally ESCC in Japan [3]. In 2008, our institution also introduced NAC, consisting of cisplatin and 5-FU, for patients with resectable locally advanced ESCC and this regimen has been offered in earnest since 2010. Accordingly, the number of operations after NAC has increased. However, the surgery for EC after chemotherapy is often made more difficult by edema and fibrous tissue changes in the mediastinal surgical field. Recently, ThE for EC has been become a more common procedure because of decreased destructive invasiveness in the chest wall and lower rates of pulmonary complications $[1,12]$. Furthermore, thoracoscopic procedures allow for detailed visualization of the anatomy under a magnified view [9]. Because NAC is standard therapy in Japan, the number of patients who undergo ThE after NAC is increasing.

Some studies indicate that chemotherapy does not impair the likelihood of esophagectomy curing or controlling cancer, and that it does not increase perioperative morbidity and mortality [4, 6, 7], even for ThE [13]. With respect to neoadjuvant chemoradiation therapy, which is the standard treatment in Western countries, several trials suggest that operative risk and postoperative morbidity and mortality rates are not increased $[4,14]$. Furthermore, some reports have demonstrated ThE to be feasible after neoadjuvant chemoradiation therapy $[15,16]$. The present study showed no differences between the NAC group and the non-NAC group in operative outcomes, or postoperative morbidity and mortality. Preoperative anemia and thrombopenia were more common in the NAC group than the non-NAC group, but this was not associated with a higher frequency of intraoperative blood transfusion in the NAC group. It cannot be denied that these operative and postoperative outcomes were influenced by the learning curve effect of 
ThE after the full implentation of NAC in 2010. However, we had performed ThE for more than 300 patients prior to April 2007, the period of enrollment began. We think that the learning curve effect had little influence on the outcomes. Although the present study is retrospective, its findings suggest that ThE can be performed safely with high procedural quality, even in patients who received NAC. However, preoperative chemotherapy and chemoradiation therapy are associated with edematous and fibrous tissue changes. When trying to achieve good responses for bulky tumors, tissue changes can be severe, with disintegration of the laminar structure around the tumor. These changes can increase the difficulty of dissection between the anatomical planes, and the likelihood of bleeding and injury to adjacent organs. A magnified view by thoracoscopy is considered useful even in such conditions.

Following NAC, it is important to carefully observe the state of the esophagus and surrounding tissue during dissection. Especially during thoracoscopic procedures, we must pay much close attention because of the technical limitations that differ from those of open surgery. It has been reported that the mortality after esohagectomy was significantly impacted by hospital volume [17] and that sufficient cases were needed to guarantee the quality of ThE [18]. This warning is also applicable to ThE. Therefore, the indication for ThE after NAC should be decided carefully at low-volume hospitals. Because the anatomy of the mediastinum is complicated and procedural problems can have critical and fatal outcomes, conversion to open surgery should be performed without hesitation.

In conclusion, we found no differences between the NAC group and the non-NAC group in terms of operative outcomes, and postoperative morbidities and mortality. These findings indicate that thoracoscopic esophagectomy with lymph node dissection for locally advanced esophageal cancer is safe and feasible, even after neoadjuvant chemotherapy.

\section{Compliance with ethical standards}

Conflict of interest Yushi Fujiwara and his co-authors have no conflicts of interest. 


\section{References}

1 Pennathur A, Gibson MK, Jobe BA, Luketich JD. Oesophageal carcinoma. Lancet. 2013;381:400-412.

2 Rustgi AK, El-Serag HB. Esophageal carcinoma. N Engl J Med. 2014;371:2499-2509.

3 Kuwano H, Nishimura Y, Oyama T, Kato H, Kitagawa Y, Kusano M, et al. Guidelines for Diagnosis and Treatment of Carcinoma of the Esophagus April 2012 edited by the Japan Esophageal Society. Esophagus. 2015;12:1-30.

4 Kranzfelder M, Schuster T, Geinitz H, Friess H, Büchler P. Meta-analysis of neoadjuvant treatment modalities and definitive non-surgical therapy for oesophageal squamous cell cancer. Br J Surg. 2011;98:768-783.

5 Ando N, Kato H, Igaki H, Shinoda M, Ozawa S, Shimizu H, et al. A randomized trial comparing postoperative adjuvant chemotherapy with cisplatin and 5-fluorouracil versus preoperative chemotherapy for localized advanced squamous cell carcinoma of the thoracic esophagus (JCOG9907). Ann Surg Oncol. 2012;19:68-74.

6 Hirao M, Ando N, Tsujinaka T, Udagawa H, Yano M, Yamana H,et al. Influence of preoperative chemotherapy for advanced thoracic oesophageal squamous cell carcinoma on perioperative complications. Br J Surg 2011;98:1735-1741.

7 Kelsen DP, Ginsberg R, Pajak TF, Sheahan DG, Gunderson L, Mortimer J, et al. Chemotherapy followed by surgery compared with surgery alone for localized esophageal cancer. N Engl J Med. 1998;339:1979-1984.

8 Lofts FJ, Falk SJ, Iveson TJ, Smith DB, Langley RE, Verma M, et al. Perioperative chemotherapy versus surgery alone for resectable gastroesophageal cancer. N Engl J Med. 2006;355:11-20.

9 Osugi H, Takemura M, Lee S, Nishikawa T, Fukuhara K, Iwasaki H, et al. Thoracoscopic esophagectomy for intrathoracic esophageal cancer. Ann Thorac Cardiovasc Surg. 2005;11:221227.

10 Sobin LH, Gospodarowicz MK, Wittekind C. TNM classification of malignant tumors. 7th ed. Oxford: Wiley-Blackwell, 2010. 
11 Katayama H, Kurokawa Y, Nakamura K, Ito H, Kanemitsu Y, Masuda N, et al. Extended ClavienDindo classification of surgical complications: Japan Clinical Oncology Group postoperative complications criteria. Surg Today. 2016;46:668-685.

12 Biere SS, van Berge Henegouwen MI, Maas KW, Bonavina L, Rosman C, Garcia JR, et al. Minimally invasive versus open oesophagectomy for patients with oesophageal cancer: a multicentre, open-label, randomised controlled trial. Lancet. 2012;379:1887-1892.

13 Tanaka E, Okabe H, Tsunoda S, Obama K, Kan T, Kadokawa Y, et al. Feasibility of thoracoscopic esophagectomy after neoadjuvant chemotherapy. Asian J Endosc Surg. 2012 5: 111-117.

14 van Hagen P, Hulshof MC, van Lanschot JJ, Steyerberg EW, van Berge Henegouwen MI, et al. Preoperative chemoradiotherapy for esophageal or junctional cancer. $\mathrm{N}$ Engl $\mathrm{J}$ Med. 2012;366:2074-2084.

15 Warner S, Chang YH, Paripati H, Ross H, Ashman J, Harold K, et al. Outcomes of minimally invasive esophagectomy in esophageal cancer after neoadjuvant chemoradiotherapy. Ann Thorac Surg. 2014 97:439-445.

16 Ben-David K, Rossidis G, Zlotecki RA, Grobmyer SR, Cendan JC, Sarosi GA, et al. Minimally invasive esophagectomy is safe and effective following neoadjuvant chemoradiation therapy. Ann Surg Oncol. 2011;18:3324-3329.

17 Fuchs HF, Harnsberger CR, Broderick RC, Chang DC, Sandler BJ, Jacobsen GR, et al.Mortality after esophagectomy is heavily impacted by center volume: retrospective analysis of the Nationwide Inpatient Sample. Surg Endosc. 2016;doi: 10.1007/s00464-016-5251-9

18 Oshikiri T, Yasuda T, Hasegawa H, Yamamoto M, Kanaji S, Yamashita K, et al. Short-term outcomes and one surgeon's learning curve for thoracoscopic esophagectomy performed with the patient in the prone position. Surg Today. 2017;47:313-319. 
legends

Table 1. Clinical characteristics of the patients

Table 2. Operative Outcomes

Table 3. Postoperative morbidity and mortality 
Table 1 Clinical characteristics of the patients

\begin{tabular}{|c|c|c|c|c|}
\hline & & non-NAC & NAC & \\
\hline & & $(n=86)$ & $(n=139)$ & $p$ \\
\hline \multicolumn{2}{|c|}{ Age, years ${ }^{\dagger}$} & $65(44-88)$ & $65(43-79)$ & 0.700 \\
\hline \multicolumn{5}{|c|}{ Sex } \\
\hline & male & 65 & 109 & 0.627 \\
\hline & female & 21 & 30 & \\
\hline \multicolumn{5}{|c|}{ Tumor location } \\
\hline & Upper thorax & 8 & 9 & 0.638 \\
\hline & Middle thorax & 42 & 75 & \\
\hline & Lower thorax & 36 & 55 & \\
\hline \multicolumn{5}{|c|}{ Clinical T categories } \\
\hline & $1 \mathrm{a}$ & 2 & 2 & 0.479 \\
\hline & $1 b$ & 11 & 24 & \\
\hline & 2 & 32 & 40 & \\
\hline & 3 & 41 & 73 & \\
\hline \multicolumn{5}{|c|}{ Clinical N categories } \\
\hline & 0 & 31 & 8 & $<0.001$ \\
\hline & 1 & 46 & 110 & \\
\hline & 2 & 9 & 21 & \\
\hline \multicolumn{5}{|c|}{ Clinical stage } \\
\hline & IB & 20 & 4 & $<0.001$ \\
\hline & IIA & 11 & 4 & \\
\hline & IIB & 24 & 59 & \\
\hline & IIIA & 24 & 54 & \\
\hline & IIIIB & 7 & 18 & \\
\hline \multicolumn{5}{|c|}{ Neoadjuvant chemotherapy } \\
\hline & 1 cycle & - & 52 & \\
\hline & 2 cycles & - & 87 & \\
\hline \multicolumn{5}{|c|}{ Preoperative blood test } \\
\hline & WBC $\left(10^{9} / \mathrm{L}\right)$ & $6.0[5.2-6.9]$ & $5.6[4.6-7.1]$ & 0.057 \\
\hline & $\operatorname{RBC}\left(10^{12} / \mathrm{L}\right)$ & $4.30[3.92-4.53]$ & $3.77[3.45-4.04]$ & $<0.001$ \\
\hline & $\mathrm{Hb}(\mathrm{g} / \mathrm{L})$ & $131[123-144]$ & 120 [112-129] & $<0.001$ \\
\hline & $\mathrm{Ht}(/ \mathrm{L})$ & $0.393[0.371-0.426]$ & $0.357[0.332-0.379]$ & $<0.001$ \\
\hline & Platelets $\left(10^{9} / \mathrm{L}\right)$ & 237 [206-287] & $207[168-248]$ & 0.009 \\
\hline & BUN (mmol/L) & $4.6[3.9-5.7]$ & $6.1[5.0-7.1]$ & $<0.001$ \\
\hline & Cre $(\mu \mathrm{mol} / \mathrm{L})$ & $62.8[54.8-74.5]$ & $75.1[65.0-90.2]$ & $<0.001$ \\
\hline & $\mathrm{eGFR}\left(\mathrm{mL} / \mathrm{min} / 1.73 \mathrm{~m}^{2}\right)$ & $76.8[64.3-90.3]$ & $64.3[55.4-75.7]$ & 0.001 \\
\hline \multicolumn{5}{|c|}{ ASA classification } \\
\hline & 1 & 20 & 43 & 0.109 \\
\hline & 2 & 66 & 92 & \\
\hline & 3 & 0 & 4 & \\
\hline
\end{tabular}

values are ${ }^{\dagger}$ median (range), ${ }^{\dagger}$ median[inter-quartile range], WBC White blood cell count, RBC Red blood cell count, $\mathrm{Hb}$ hemoglobin, $\mathrm{Ht}$ hematocrit, BUN blood urea nitrogen, Cre creatinine, eGFR estimated glemerular filtration rate, ASA American Society of Anesthesiologist 
Table 2 Operative Outcomes

\begin{tabular}{|c|c|c|c|c|}
\hline & & Non-NAC & $\mathrm{NAC}$ & \\
\hline & & $(n=86)$ & $(\mathrm{n}=139)$ & $p$ \\
\hline Conversion to open (\%) & & $6(7.0)$ & $14(10.7)$ & 0.480 \\
\hline $\mathrm{T} 4$ & & 4 & 4 & \\
\hline Pleural adhesion & & 2 & 9 & \\
\hline Damage of other organ & & 0 & 1 & \\
\hline Operative time $(\min )^{\dagger}$ & & $411(294-995)$ & $419(295-726)$ & 0.663 \\
\hline Thoracic procedure time $(\mathrm{min})^{\dagger}$ & & $191(123-334)$ & $184(118-313)$ & 0.259 \\
\hline Blood loss $(\mathrm{g})^{\dagger}$ & & $475(85-1300)$ & $450(125-1130)$ & 0.937 \\
\hline $\begin{array}{l}\text { Blood loss of thoracic } \\
\text { procedure }(\mathrm{g})^{\dagger}\end{array}$ & & $180(15-790)$ & $150(20-590)$ & 0.513 \\
\hline No. of dissected LNs ${ }^{\dagger}$ & & $56(28-111)$ & $56(28-99)$ & 0.795 \\
\hline $\begin{array}{l}\text { No. of dissected LNs in } \\
\text { thoracic part }\end{array}$ & & $32(13-86)$ & $32(11-72)$ & 0.607 \\
\hline \multirow[t]{2}{*}{ Transfusion } & + & 6 & 11 & 0.796 \\
\hline & - & 80 & 128 & \\
\hline
\end{tabular}

values are ${ }^{\dagger}$ median (range); LNs, lymph nodes 
Table 3 Postoperative morbidity and mortality

\begin{tabular}{|c|c|c|c|c|}
\hline & & Non-NAC & NAC & \\
\hline & & $(n=86)$ & $(n=139)$ & $p$ \\
\hline \multicolumn{2}{|c|}{ Surgical Site Infection } & $7(8.1 \%)$ & $11(2.9 \%)$ & 0.110 \\
\hline \multicolumn{2}{|c|}{ Pneumonia } & $10(11.6 \%)$ & $15(10.8 \%)$ & 0.831 \\
\hline \multicolumn{2}{|c|}{ Recurrent laryngeal nerve paralysis } & $22(25.6 \%)$ & $30(23.1 \%)$ & 0.518 \\
\hline \multicolumn{2}{|c|}{ Anastomotic leakage } & $12(14.0 \%)$ & $25(18.0 \%)$ & 0.465 \\
\hline \multicolumn{2}{|c|}{ Chyle leakage } & $4(4.7 \%)$ & $5(3.6 \%)$ & 0.735 \\
\hline \multicolumn{5}{|l|}{ Death } \\
\hline & In hospital & $0(0.0 \%)$ & $0(0.0 \%)$ & - \\
\hline & Within 90 days & $1(1.2 \%)$ & $0(0.0 \%)$ & 0.382 \\
\hline \multicolumn{2}{|c|}{ Hospital Days $^{\dagger}$} & $28(14-217)$ & $27(15-186)$ & 0.239 \\
\hline
\end{tabular}

${ }^{\dagger}$ values are median (range) 